NASA

Technical Memorandum 101381

AIAA-89-0769
AVSCOM

Technical Report 88-C-036

\title{
Performance of the Forward Scattering Spectrometer Probe in NASA's Icing Research Tunnel
}

Edward A. Hovenac

Sverdrup Technology, Inc.

NASA Lewis Research Center Group

Cleveland, Ohio

and

Robert F. Ide

Propulsion Directorate

U.S. Army Aviation Research and Technology Activity-AVSCOM

Lewis Research Center

Cleveland, Ohio

(AASA-TE-1C1J81) EERECKMAACE CE THE ECBAAED

SCATAERING SELCIFCEETEF PFCEE IA NASAIS

$\operatorname{Na9-1<245}$

ICING GESEAGCL JUAML (NASA)

$11 \mathrm{p} C S C L 14 \mathrm{E}$

Unclas

Prepared for the

27th Aerospace Sciences Meeting

sponsored by the American Institute of Aeronautics and Astronautics

Reno, Nevada, January 9-12, 1989 
PERFORMANCE OF THE FORWARD SCATTERING SPECTROMETER PROBE

IN NASA'S ICING RESEARCH TUNNEL

Edward A. Hovenac

Sverdrup Technology, Inc.

NASA Lewis Research Center Group

Cleveland, Ohio 44135

and

Robert F. Ide

Propulsion Directorate

U.5. Army Aviation Research and Technology Activity - AVSCOM

National Aeronautics and Space Amdinistration

Cleveland, Ohio 44135

\section{Abstract}

Two Forward Scattering Spectrometer Probes were used to measure droplet distributions in the NASA Lewis Research Center's Icing Research Tunnel. The instruments showed good agreement when the median volume diameter (MVD) was approximately $16 \mu \mathrm{m}$. Coincidence events affected much of the data and caused the measured MVD to be about 2 to $3 \mu \mathrm{m}$ larger than expected. Coincidence events were reduced by shutting down half of the spray bars in the tunnel during certain tests.

\section{Introduction}

During 1987 the Icing Research Tunnel (IRT) at NASA Lewis was refurbished. When the work was completed various tunnel parameters needed to be measured ( $i . e$ air velocity, temperature, cloud uniformity, liquid water content, etc.) to determine how well the tunnel simulated natural icing conditions. One parameter that needed to be measured was the droplet size distribution in the tunnel cloud. The goal was to determine the droplet size distribution and the median volume diameter (MVD) for various tunnel set points. The instruments used to make this measurement were two different models of the Forward Scattering Spectrometer Probe (FSSP) manufactured by Particle Measuring Systems, Inc. of Boulder, Colorado.

The subject of this paper is the performance of the FSSP in the Icing Research Tunnel. The IRT test covered a range of tunnel conditions. This provided an ideal opportunity to evaluate the instruments under a variety of controlled conditions.

\section{Test Procedures}

\section{Instrumentation}

Two FSSP's were used throughout the IRT test. The first has four size ranges: range 0 is 2 to $47 \mu \mathrm{m}$, range 1 is 2 to $32 \mu \mathrm{m}$, range 2 is 1 to $16 \mu \mathrm{m}$, and range 3 is 0.5 to $8 \mu \mathrm{m}$. It will be referred to as the FSSP47. The second FSSP al so has 4 ranges: range 0 is 5 to $95 \mu \mathrm{m}$, range 1 is 2 to $47 \mu \mathrm{m}$, range 2 is 2 to $32 \mu \mathrm{m}$, and range 3 is 1 to $16 \mu \mathrm{m}$. It will be referred to as the FSSP95. For more detailed information on the theory of operation of the FSSP consult Refs. I to 3 .

The FSSP measures droplets as they pass through the instrument's laser beam. Each droplet is classified in size categories or bins. Each of the four ranges has 15 size bins. The number of droplets in each size bin (also called the number distribution) is then used for further calculations. For icing research the important quantities that are calculated from the number distribution are the percent volume distribution and the median volume diameter (MVO).

\section{FSSP Calibration}

The calibration of both FSSPS was checked every day prior to running in the IRT. The device used to check the calibration was a rotating pinhole developed at NASA Lewis. The instrument, shown in Fig. 1, consists of a calibration pinhole of a known diameter which is attached to a motor and rotated through the sample volume of the FSSP. The diameter pinhole can be from 1 to $50 \mu \mathrm{m}$. A $15 \mu \mathrm{m}$ pinhole was typically used throughout the testing period. When this pinhole passes through the sample volume it simulates a $9 \mathrm{\mu m}$ water droplet scattering light. This method provides an absolute size calibration of the FSSP.

Data in Fig. 2(a) show the calibration of the FSSP47 and the FSSP95 prior to several test runs in the IRT. This data is from the 2 to $47 \mu \mathrm{m}$ range for both instruments. This was the range most often used for the data analysis. Note that the FSSP 47 appears to oversize smaller water droplets by about one bin or $3 \mu m$.

Using the rotating pinhole to check the calibration provided a rellable method of checking the operation of the FSSP after a run to determine if any undetected problems arose during the test. To illustrate this, Fig. $2(b)$ shows the calibration before and after one test. The marked decrease in the FSSP95 response to the pinhole was traced to water collecting on the recelving optics. After the water was dried off and the lenses cleaned, the calibration came back up to its nominal value.

\section{Measurements in Wind Tunnel Clouds}

\section{Distributions for Different Tunnel Set Points}

Throughout the IRT test, the nozzle water and air pressures were varied. The effect of increasing the water pressure is shown in Fig. $3(a)$. The droplets become larger as water pressure increases.

OR:GNAL FESTE 

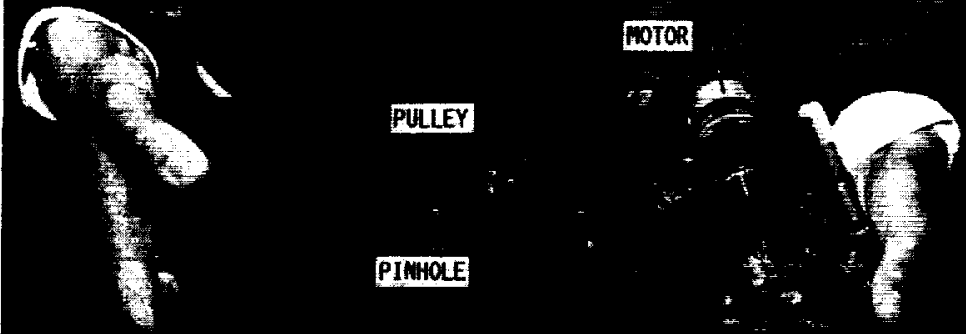

\section{MICROPOSIIIOAER}

C-88-06824

(a) COMPONENTS ON THE PINHOLE CALIBRATOR.

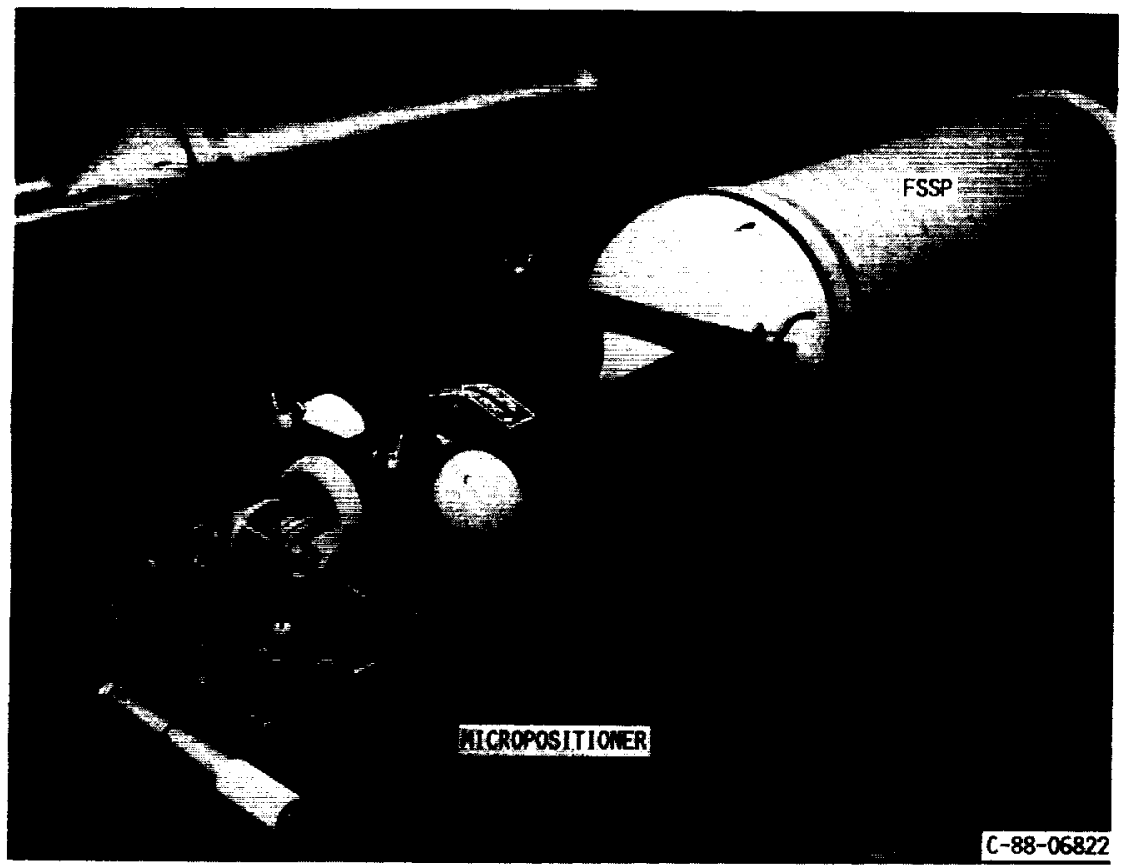

(b) PINHOLE CALIBRATOR ATTACHED TO FSSP.

FIGURE 1. - THE ROTATING PINHOLE USED FOR CAL IBRATION. 


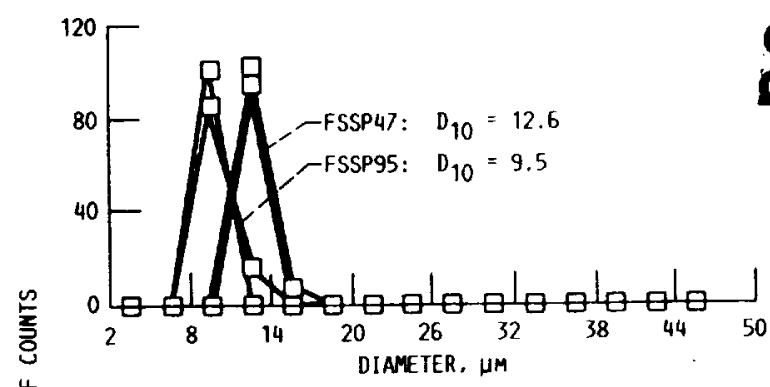

ORIGINA: Pran is OF POOR QUALIIY

(a) COMPARES THE CAL IBRATION OF THE FSSP47 WITH THE CAL IBRATION OF THE FSSP95.

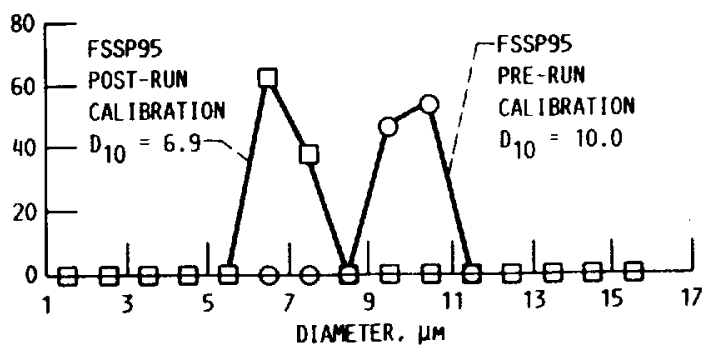

(b) SHOWS HOW HATER COLLECTING ON THE LENS OF THE FSSP9S AFFECIED ITS CAL IBRATION.

FIGURE 2. - CALIBRAIION OF THE FSSP USING THE PINHOLE ROTATOR.

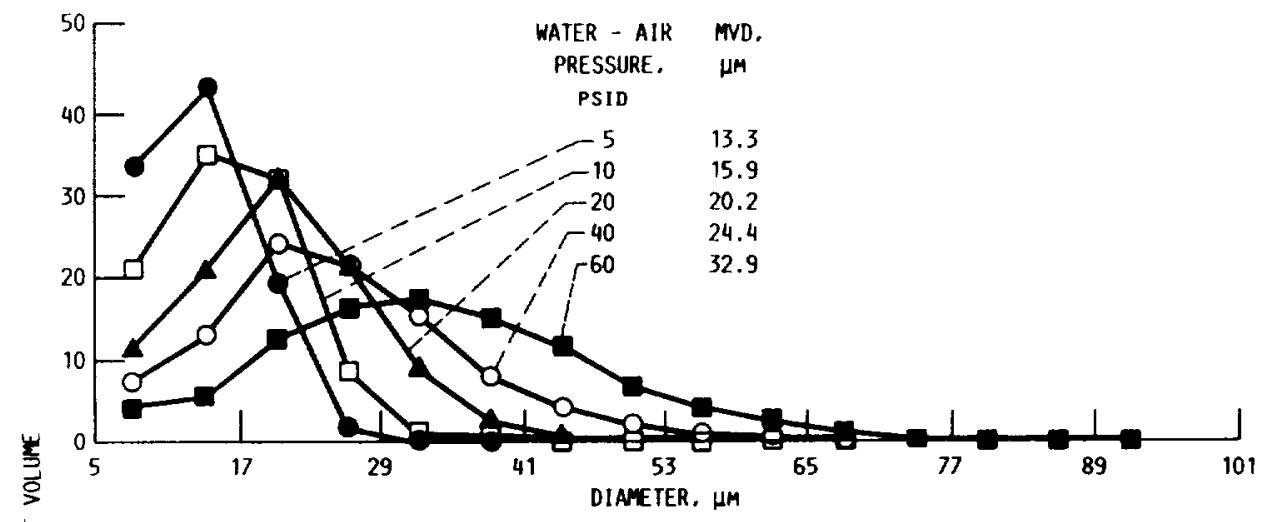

(a) DROPLETS BECONE LARGER AS NOZZLE MATER PRESSURE INCREASES.

突

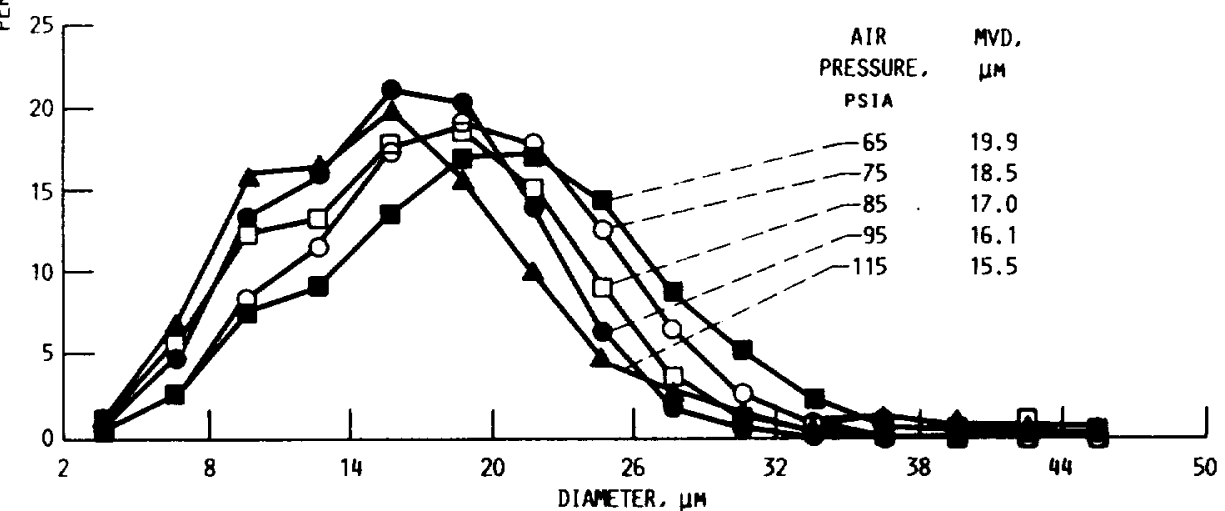

(b) DROPLETS BECOME SMALLER AS MOZZLE AIR PRESSURE INCREASES.

FIGURE 3. - TYPICAL DISTRIBUTIONS PRODUCED IN THE IRT BY VARYING TUMNEL CONDITIONS. 
Figure $3(b)$ shows the effect on water droplets as nozzle air pressure is increased. The droplets become smaller.

Activity

The FSSP measures a quantity called activity. It is defined as the percent of time the instrument is busy analyzing particles. An equation describing activity is given as:

$$
\text { Activity }=100 *\left(T_{t}+D_{t}\right) / E_{t} \text {. }
$$

Where $T_{t}$ is the sum of the transit time of a 11 particles through the probe volume. $D_{t}$ is the sum of all the periods of dead time when the instrument is analyzing a particle and is insensitive to other particles in the sample volume. And $E_{t}$ is the total elapsed time the FSSP is running.

Activity is a good method of determining whether the instrument is becoming overwhelmed with too many particles. It is best to make measurements when the activity is less than 80 percent.

Figure $4(a)$ and (b) shows the measured activi. ty (along the $x$-axis) for all the runs using the FSSP47 and the FSSP95 respectively during the IRT test. In both plots the circles represent range 0 and the boxes range 1. Note that many of the runs were with activities that were larger than the recommended 80 percent.

Also note that the FSSP95 (Fig. $4(\mathrm{~b})$ ) had generlly lower activities in the 5 to 95 range than the 2 to 47 range. This was due to the effect of droplets below $5 \mu \mathrm{m}$. There were a large number of these small droplets. In the 2 to 47 range the FSSPS5 had to analyze these droplets. This contributed to the overall increase in activity in that range. For the 5 to 95 range, droplets less than $5 \mu \mathrm{m}$ were not analyzed by the instrument and therefore did not contribute to the activity.

The FSSP47 (Fig. $4(a)$ ) does not show a significant difference between the activities for range 0 and range 1 (both vary from 40 to 90 percent).

This because both range 0 and range 1 start at $2 \mu \mathrm{m}$ on that instrument.

\section{Valid Count/Total Strobe Ratio}

The $y$-axis along Fig. $4(a)$ and (b) indicates the ratio of valid counts to total strobes (VC/TS). The valid counts are the sum of all the counts in all 15 size bins in the FSSP. Droplets that go through the radially central region of the laser beam generate valid counts and total strobes. Oroplets that go through outer reglons of the laser beam only generate total strobes. The ratio of VC/TS is a measure of the fractional part of the beam diameter (or the effective beam diameter) that is used for measuring the droplets. This is used for determining the probe volume in the FSSP.

Figure $4(a)$ and (b) shows the VC/TS ratio decreases as activity increases. In the PMS manual the specifications for the FSSP95 give the VC/TS ratio as 0.5 . The manual also notes that increased particle velocities can lower this ratio and recommends measuring the actual value on line to determine it more accurately. This, however is not the reason for the decrease in the VC/TS ratio because

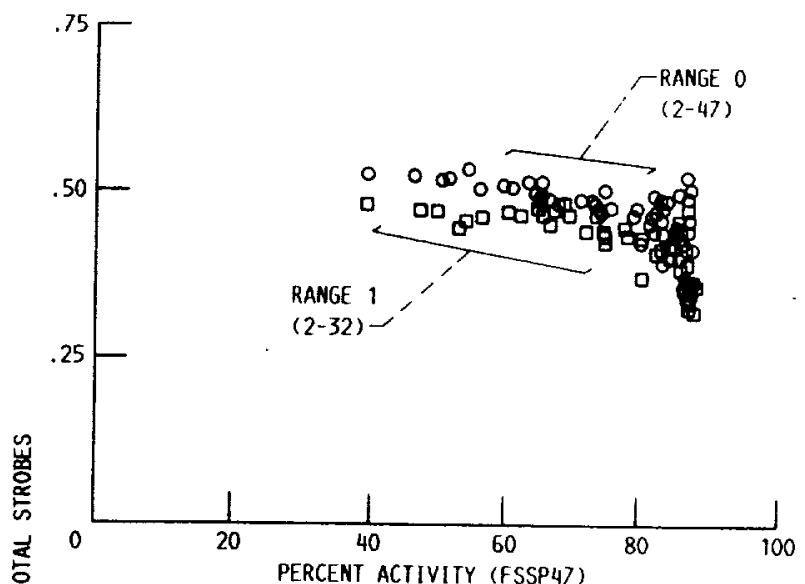

(a) DATA FROM THE FSSP 47

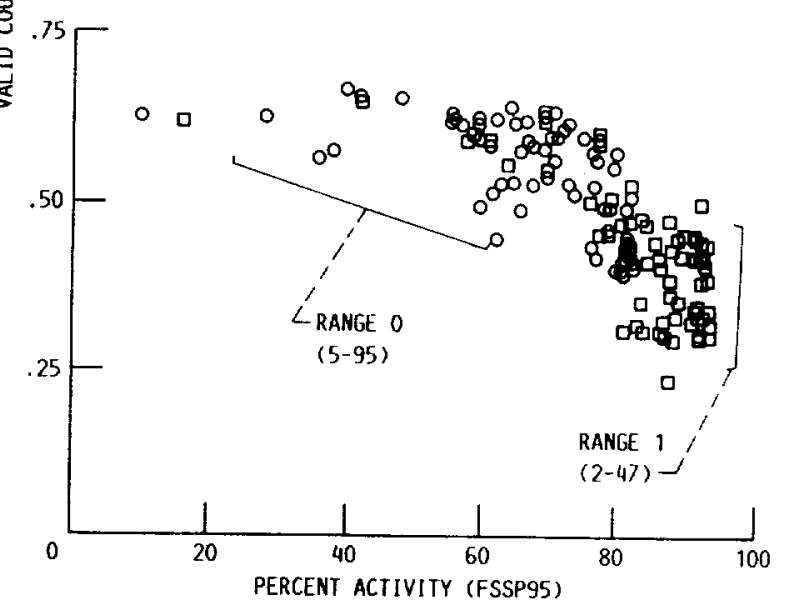

(b) DATA FROM THE FSSP95.

FIGURE 4. - ACTIVITY IN THE FSSP'S. CIRCLES ARE FOR RANGE 0 . BOXES ARE FOR RANGE 1 .

all the runs were made at the same velocity $(67 \mathrm{~m} / \mathrm{s})$. The manual also mentions that coincidence events can decrease the ratio. Since activity is related to coincidence events, (see Ref. 4) this is most likely the cause for the decrease.

Coincidence events affect the VC/TS ratio in an indirect manner. When a particle crosses the laser beam, the FSSP must determine if the particle went through the central region of the beam ( $i . e$. . the effective beam diameter). The FSSP does this by measuring the duration of time the particle was in the beam (its transit time). If the particle was in the beam for a period of time that was less than the average time for all the previous particles, it is assumed the particle went through a chord near the edge of the beam. If the particle was in the beam for a period of time that was greater than the average time for all the previous particles, it is assumed the particle went through the central region of the beam. This generates a valid count.

During a coincidence event one particle enters the beam before the previous one has left. This appears to the FSSP as one particle with a long transit time. If enough coincidence events occur. then the running average of the transit times starts to increase. As the average transit time increases 
due to coincidence events, the probability of single particles residing in the beam longer than this average will decrease. Thus, the effective beam diameter becomes diminished and the VC/TS ratio reflects this.

There are two implications of this analysis. First, for this test (i.e., cloud velocities of $67 \mathrm{~m} / \mathrm{s}$ ) it appears that coincidence errors started occurring at activities as low as 80 percent in the FSSP47 and 60 percent for the FSSP95. (The FSSP 47 has fewer coincidence events because it has a smaller beam diameter.) These numbers ( 80 and 60 percent) were determined by looking at the place in Fig. 4 where the VC/TS ratio started to decrease.

The second implication is the FSSP will bias the data toward coincidence events. Since the FSSP preferentially counts particles with longer transit times, the instrument is more likely to measure coincident particles than single particle events This will bias the measured particle size distribution towards larger diameter particles.

\section{Instrument Comparison}

Since a number of spray conditions were repeated for both FSSP 47 and the FSSP95, it provided an opportunity to make an instrument comparison of particle volume distributions from both instruments. For the comparison the 2 to $47 \mu \mathrm{m}$ range was used for both instruments.

Figure $5(a)$ to (d) shows the comparison between the two instruments over a range of droplets sizes. The distributions show falr agreement. The MVO measured on the FSSP47 differed by less than 15 percent when compared to the MVD measured on the FSSP95.

Throughout the IRT test, there were a total of 12 runs in which tunnel conditions were ldentical for both the FSSP47 and the FSSP95. The MVD for the FSSP47 versus the FSSP95 is plotted in Fig. 6. Note that the FSSP47 oversizes the cloud (relative to the FSSP95) if the bulk of the mass is contained in small droplets. This was expected from the pinhole calibration. For large droplets the FSSP47 measured MVDS that were smaller than the FSSP95 measured. The cross over point is about $16 \mu \mathrm{m}$.

\section{Coincidence Errors}

The high activities encountered during the test indicated that coincidence errors could be affecting the measured distribution. To test this half of the spray bars were shut down. This theoretically reduced the number density without changing the particle size.

Figure $7(a)$, (b), and (c) shows three different pairs of distributions for the 5 to $95 \mu \mathrm{m}$ range on the FSSP95. One distribution is with half of the spray bars on and the other is with all the spray bars on. In figure $7(a)$ and (b) the distributions are very close and the MVD is within 2 percent. The MVOs in figure $7(c)$ differ by 18 percent. This larger discrepancy is probably due to the effects of coincidence on this wider distribution.

The plots in figure $7(d),(e)$, and (f) are the same as figure $7(a),(b)$, and (c) except the FSSP95 was set on the 2 to $47 \mu m$ range. In this case the
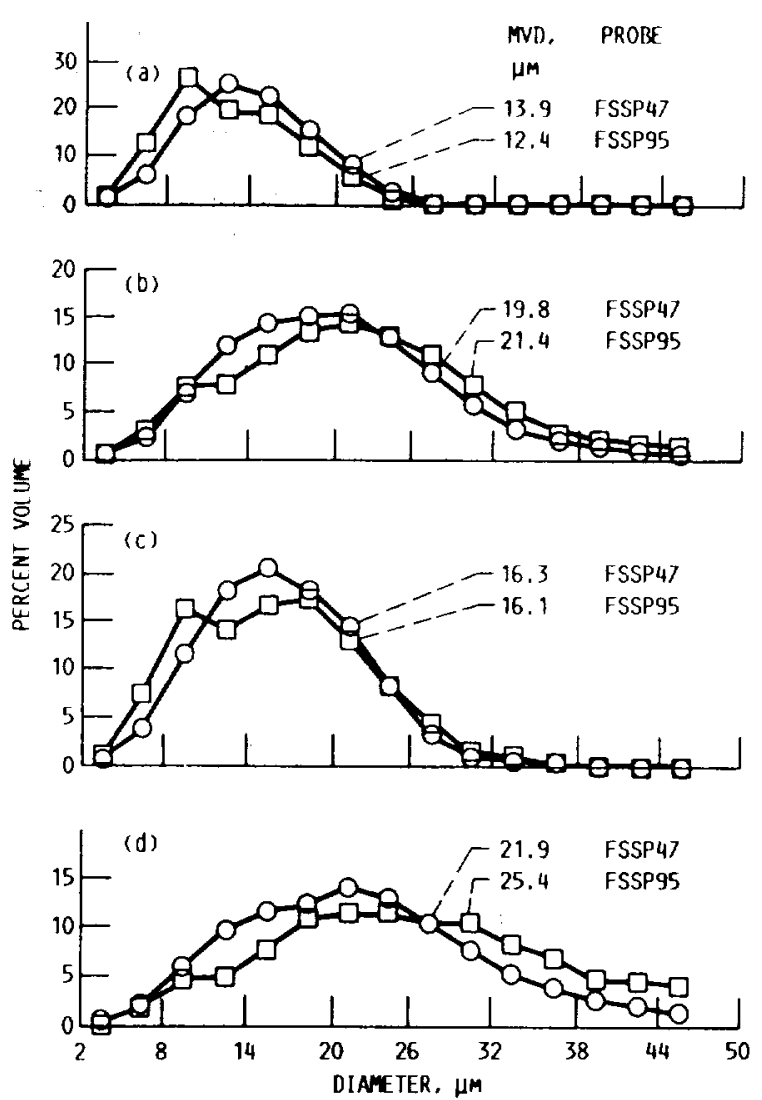

FIGURE 5. - COMPARISON OF VOLUME DISIRIBUTIONS REASURED BY THE FSSP47 WITH THOSE MEASURED BY THE FSSP95.

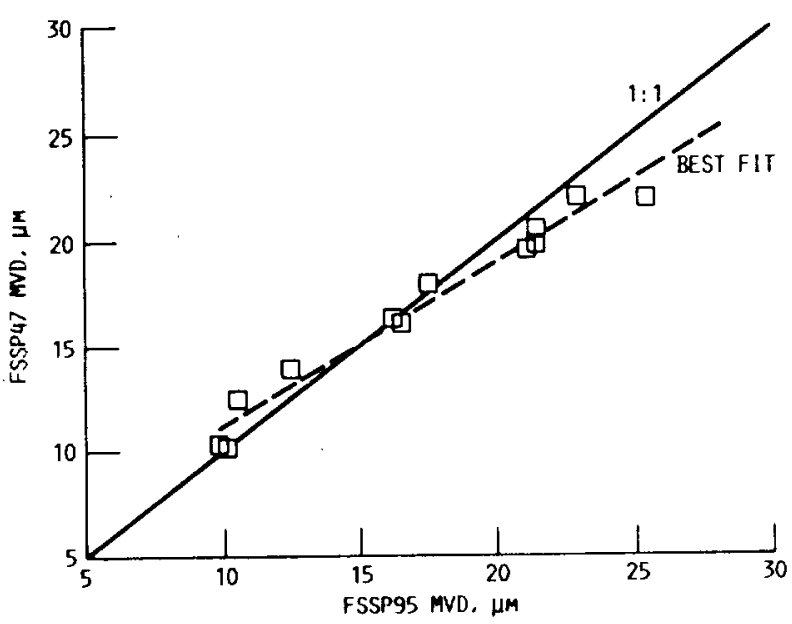

FIGURE 6. - COMPARISON OF THE MVD MEASURED BY THE FSSP47 WITH THE MVD MEASURED BY THE FSSP95.

MDs differed a bit more: 10 to 20 percent for all three cases. The distribution with the higher activity always had the higher MVD. Coincidence events are the probable cause for this difference.

Figure $8(a)$ and (b) shows plots of the measured MVD in the tunnel with half of the spray bars running versus the MVD with all the spray bars running. The best fit line through the data indicates there was oversizing by about 2 to $3 \mu \mathrm{m}$ when all of the spray bars were running. Coincidence events are the most. likely cause of this error. 


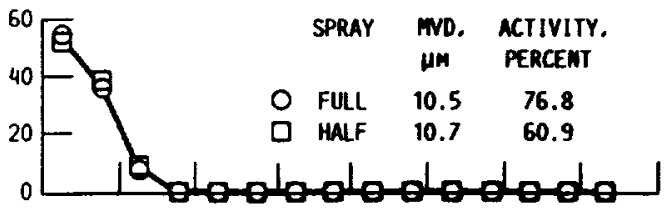

(a) FSSP9S RANGE 0 .

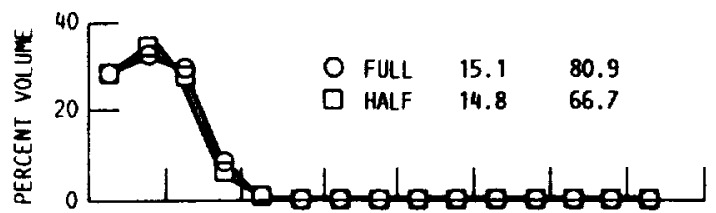

(b) FSSP9S RANGE 0 .

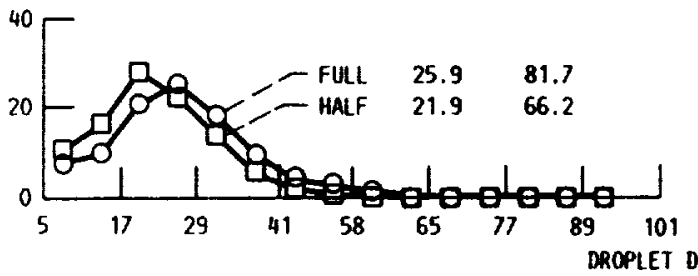

(c) FSSP9S RAMGE 0.

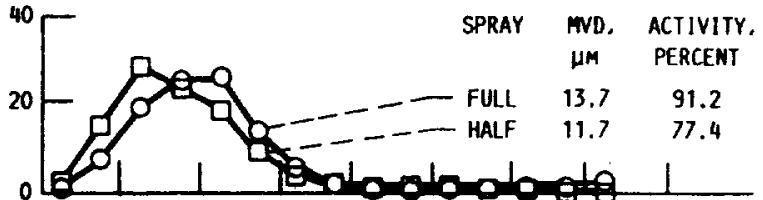

(d) FSSP95 RANGE 1

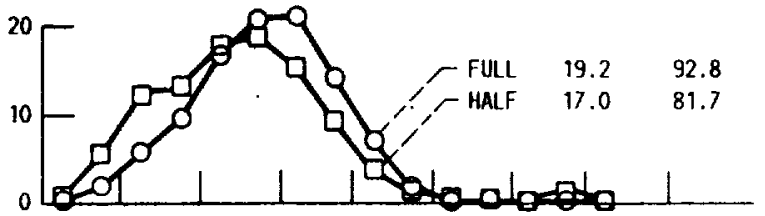

(e) FSSP95 RANGE 1.

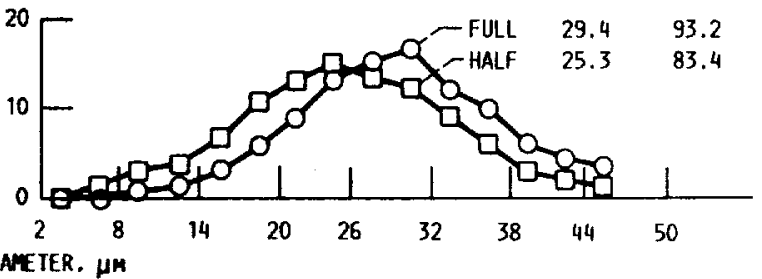

(1) FSSP95 RANGE 1.

FIGURE 7. - COMPARISON OF VOLUME DISTRIBUTIONS MEASURED MHILE HALF OF TIE SPRAY BARS WERE OPERATING WITH DISIRIBUTIONS MEASURED WHILE ALL THE SPRAY BARS IERE OPERATIMG.

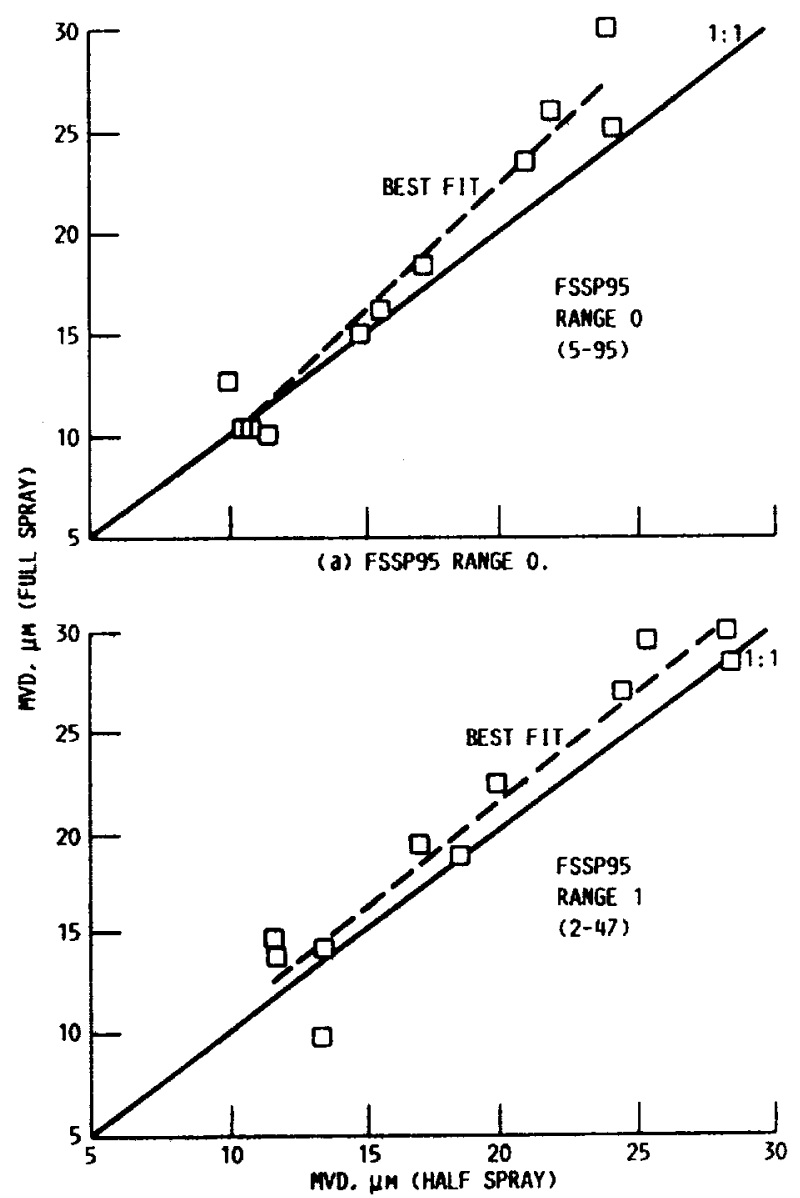

(b) FSSP95 RAMGE 1.

FIGURE 8. - COMPARISON OF THE REASURED TWD WHILE HALF OF THE SPRAY BARS WERE OPERATIMG WITH THE MVD WHILE ALL THE SPRAY BARS WERE OPERATIMG. 


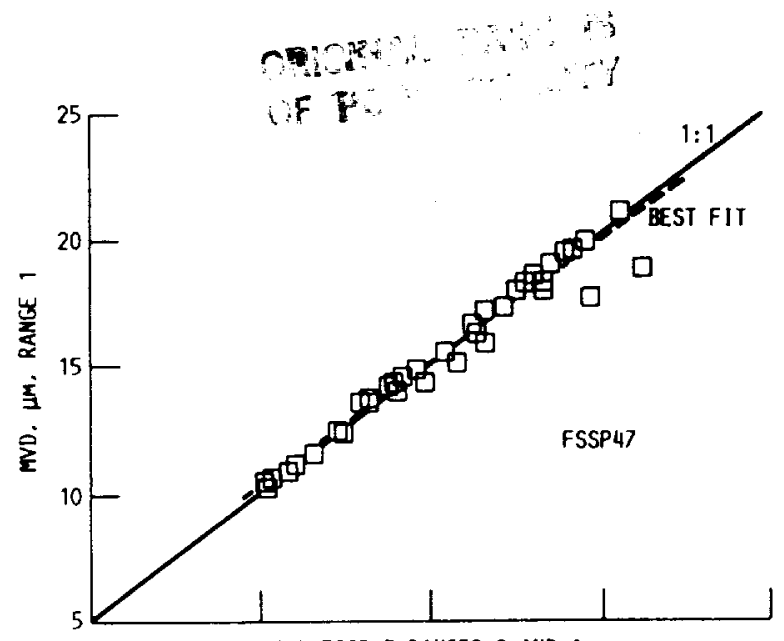

(a) FSSP47 RANGES O AND 1.

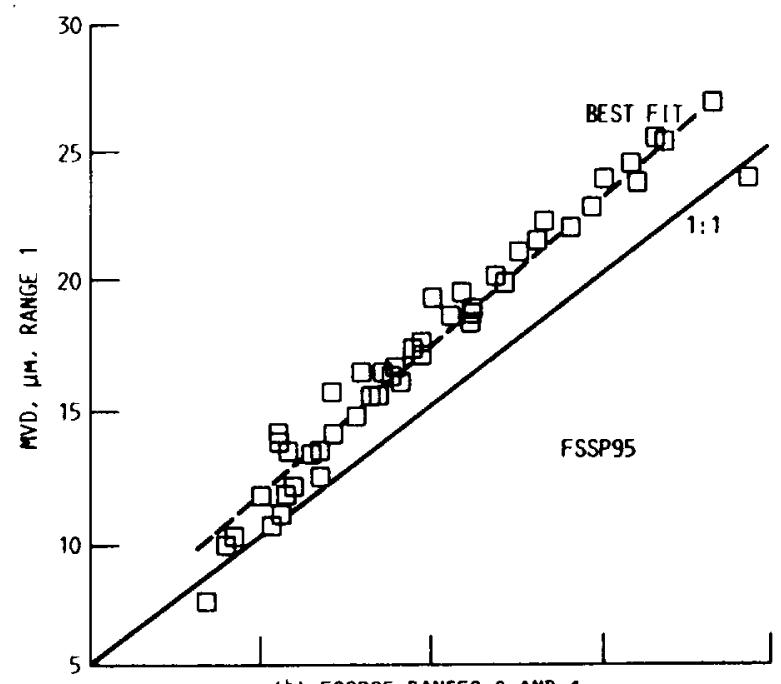

(b) FSSP95 RANGES 0 AND 1

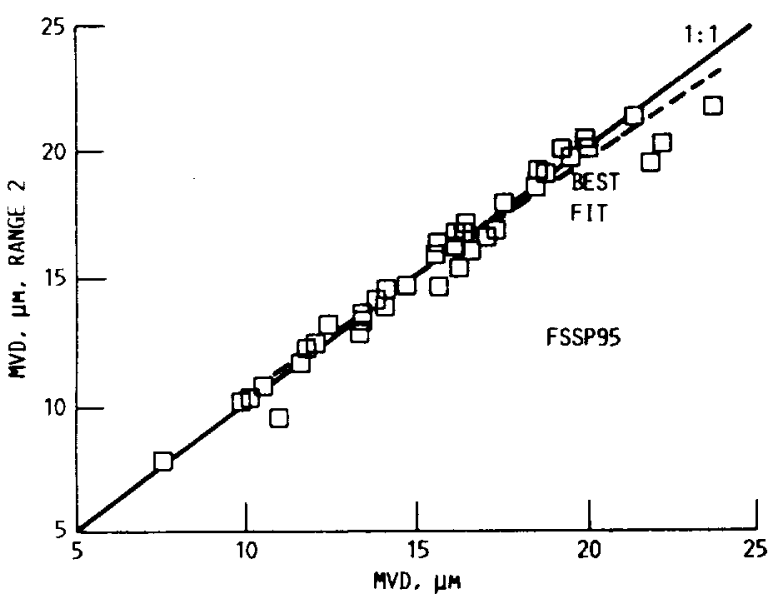

(c) FSSP95 RANGES 1 AND 2.

FIGURE 9. - COMPARISON OF THE MVD MEASURED WITH DIFFERENT RANGES OF THE SAME INSTRUMENT.
Another comparison that is of interest is the repeatability of the instrument on different ranges. Figure $g(a)$ shows the measured MVD using the FSSP47. The plot compares range $0(2$ to $47 \mu \mathrm{m})$ with range $1(2$ to $32 \mu \mathrm{m})$. The ranges agree very well. To make a valid comparison, distributions that were outside of range 1 (i.e., distributions with droplets larger than $32 \mu \mathrm{m}$ ) were not plotted.

Figure $g(b)$ shows a comparison of the measured MVD's using the FSSP95. This plot compares range 0 ( 5 to $95 \mu \mathrm{m}$ ) with range 1 ( 2 to $47 \mu \mathrm{m})$. These ranges do not agree as well. It is not known why this discrepancy exists.

Figure $g(c)$ compares range 1 with range 2 on the FSSP95. Range 1 and range 2 on the FSSP95 are the same as range 0 and range 1 on the FSSP47: (2 to $47 \mu \mathrm{m}$ ) and (2 to $32 \mu \mathrm{m}$ ) respectively. On these ranges the FSSP95 is comparable to the FSSP47.

\section{Instrument Icing}

Throughout the IRT test the instrument problem that occurred most frequently was ice buildup on the FSSP. On both FSSPs the flow straightening tube would ice up in the same peculiar manner. Ice would build up on the very front of the tube starting on the transmitter side. The ice would then build up toward the center until the air flow through the tube was choked off.

It was thought that increasing the heat in the flow straightening tube would solve the icing problem. The voltage on the heaters was turned up beyond the recommended 28 to $35 \mathrm{~V}$. This kept the ice off the front of the probe but caused another problem. The run-off from the front part of the tube collected in the unheated rear portion of the flow straightening tube. There it froze, built up, and again choked off the air flow. Increasing the voltage beyond $35 \mathrm{~V}$ was not tried because it was feared other smaller heaters inside the various optical components would burn out.

Throughout the test the probe had to be watched closely to determine when the ice was perturbing the flow. This would occur after three or four 5-minute icing runs. The tunnel would then be brought down to idle and the ice was removed from the probe. Often the ice inside the tube would have already shed by the time the tunnel velocity was down to $30 \mathrm{mph}$.

\section{Conclusions}

The two FSSPs used throughout the IRT test agreed well when the MVD was around $16 \mu \mathrm{m}$. For MVOs around 10 and $25 \mu \mathrm{m}$ the difference between the two FSSPs was 2 to $3 \mu \mathrm{m}$. Also, coincidence events probably caused an increase in the measured MVD of 2 to $3 \mu \mathrm{m}$ for many test runs. Most of the data collected was for activities in excess of 50 percent. Many times the activity was beyond 80 percent. This meant the FSSP was being operated at the very edge of its operation envelope. Shutting down half of the spray bars reduced the number density and brought the activity down to more acceptable levels. Range 0 and range 1 did not agree as well as range 1 and range 2 on the FSSP95. Ice buildup on both FSSPs caused numerous delays. 


\section{References}

1. Hovenac, E.C., "Calibration of Droplet Sizing and Liquld Water Content Instruments: Survey and Analysis," NASA CR-175099. May 1986.

2. Dye, J.E. and Baumgardner D., "Evaluation of the Forward Scattering Spectrometer Probe Part I: Electronic and Optical Studies," Journal of Atmosheric and Oceanic Technology, Vol. 1 . No. 12, Dec. 1984, pp. 329-344.
3. Forward Scattering Spectrometer Probe, PMS Model FSSP-100, Operating and Servicing Manual. Particle Measuring Systems, Inc., Boulder, CO, 1984.

4. Baumgardner, D., Strapp, W. and Oye, J.E., "Evaluation of the Forward Scattering Spectrometer Probe Part II: Corrections for Coincidence and Dead-Time Losses, "Journal of Atmospheric and Oceanic Technolgy, Vol. 2, No. 12, Dec. 1985, pp. 626-632.

\section{ORIGINAL PAGE IS OF. POOR QUALITY}




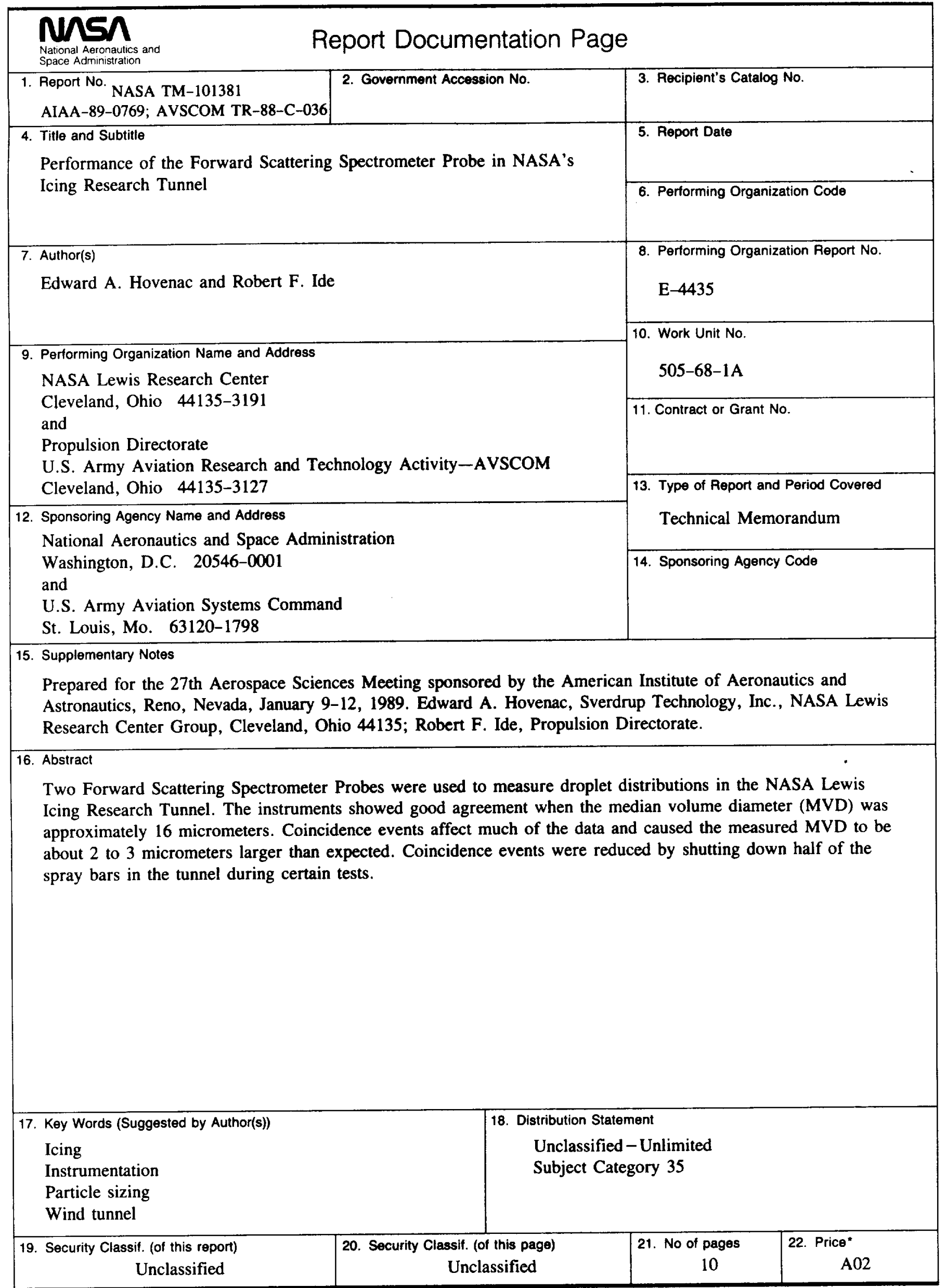


